Journal of Current and Advance Medical Research

January 2020, Vol. 7, No. 1, pp. 7-11

http://www.banglajol.info/index.php/JCAMR

ISSN (Print) 2313-447X

ISSN (Online) 2413-323X

NLM Catalog ID 101673828

DOI: https://doi.org/10.3329/jcamr.v7i1.46423

ORIGINAL ARTICLE

OPEN@ACCESS

\title{
Socio-demographic Characteristics and Incidence of CIN of Uterine Cervix among VIA Positive Women attended at a Tertiary Care Hospital in Dhaka City
}

\author{
Khurshida Samad ${ }^{1}$, Imtiaz Ahmed ${ }^{2}$, Touhid Uddin Rupom ${ }^{3}$, Fouzia Jahan ${ }^{4}$, Shimul Akter ${ }^{5}$
}

\begin{abstract}
${ }^{1}$ Assistant Professor, Department of Pathology, National Institute of Ophthalmology, Dhaka, Bangladesh; ${ }^{2}$ Associate Professor, Department of Microbiology, Col. Malek Medical College, Manikgonj, Bangladesh; ${ }^{3}$ Assistant Professor, Department of Pathology, Shaheed Tajuddin Medical College, Gazipur, Bangladesh; ${ }^{4}$ Associate Professor, Department of Pathology, Bangladesh Medical College, Dhaka, Bangladesh; ${ }^{5}$ Assistant Professor, Department of Gynaecology \& Obstetrics, Monowara Sikder Medical College, Shariatpur, Bangladesh
\end{abstract}

[Received on: 2 October 2019; Accepted on: 1 December 2019; Published on: 1 January 2020]

\section{Abstract}

Background: Women in different socio-demographic are presented with VIA positivity. Objective: The purpose of the present study was to see the socio-demographic characteristics and incidence of CIN of uterine cervix among of VIA positive women. Methodology: This cross sectional study was conducted in the Department Of Pathology at Bangabandhu Sheikh Mujib Medical University (BSMMU), Dhaka, Bangladesh during the period of July 2007 to June 2008 for one (01) year. Patients who were colposcopically positive for cervical intraepithelial neoplasia and early invasive carcinoma or patients who are colposcopically negative but clinically suspicious for cervical neoplasia were included in this study. The clinical history was obtained by taking history with particular attention to age, age at marriage, parity, history of contraceptives, abnormal per vaginal discharge and post coital bleeding. The cervix was examined on naked eye by Cusco's speculum to see whether it was healthy or not. Then it was examined by the colposcope after applying 3.0 to $5.0 \%$ acetic acid and colposcopic findings were collected. VIA positive cases were underwent colposcopy guided LEEP biopsy. Result: A total of 63 patients of different age group were recruited for this study. The mean with SD of age of this study population was $34.6 \pm 9.59$ years. In this study, $41(65 \%)$ cases were diagnosed as cervical intraepithelial neoplasia (CIN). Incidence of CIN-I was 10 cases in age group 20 to 29 years. Most of the cases were in 30 to 39 (18 cases) years age group. Among 20 cases of high grade lesion (CIN-II/III) 9(45\%) cases were in lower class, 8(40\%) cases were in middle class and 3(15\%) cases in upper class. Conclusion: In conclusion majority of the women were middle aged reproductive age group who are mostly in the lower class of socioeconomic class. [Journal of Current and Advance Medical Research, January 2020;7(1):7-11]

Keywords: Socio-demographic Characteristics; Incidence; CIN; Uterine Cervix; VIA Positive Women

Correspondence: Dr. Khurshida Samad, Assistant Professor, Department of Pathology, National Institute of Ophthalmology and Hospital, Sher-E-Bangla Nagar, Dhaka-1207, Bangladesh; Mobile: +8801552421396; Email: khurshidarmc@gmail.com

Cite this article as: Samad K, Ahmed I, Rupom TU, Jahan F, Akter S. Socio-demographic Characteristics and Incidence of CIN of Uterine Cervix among VIA Positive Women attended at a Tertiary Care Hospital in Dhaka City. J Curr Adv Med Res 2020;7(1):7-11

Funding: This study has been performed without any funding from outside else.

Conflict of Interest: There was no conflict of interest to any of the authors.

Contributions to authors: Samad K and Ahmed I involved in protocol preparation, data collection; statistical analysis Samad K, Rupom TU, Jahan F \& Akter S had involved in manuscript writing \& revision of the manuscript.

Copyright: (02020. Samad et al. Published by Journal of Current and Advance Medical Research. This article is published under the Creative Commons CC BY-NC License (https://creativecommons.org/licenses/by-nc/4.0/). This license permits use, distribution and reproduction in any medium, provided the original work is properly cited, and is not used for commercial purposes. 


\section{Introduction}

Cervical cancer is the second commonest cancer in women worldwide ${ }^{1}$. Almost $80 \%$ of these cases occur in the developing countries ${ }^{2}$. The high risk population are in Africa, Latin America and countries of Asia like India, Thailand, Philippins and Korea. In the United States the incidence rate has decreased during the last several decades both among blacks and whites, presumably as. a result of the widespread use of cervical cytological screening programs and other diagnostic facilities in the early stage of the disease ${ }^{3}$. It is the leading cause of cancer morbidity and mortality in Indian women accounting for $25 \%$ of all new cases of cancer and $23 \%$ of death due to cancer $^{2}$. There is a sharp difference between developed and developing countries in both incidence and mortality of the disease $^{4}$. In the developed countries, it is the least common cause of cancer death among women. Women of developed countries have easy access to screening test which allows detection of precancerous lesion and therefore they are treated before they developed into full-blown cancer ${ }^{5}$.

At present, in Bangladesh there are very few screening programme for prevention of cervical cancer ${ }^{6}$. Screening programme through cervical smear needs specialist (Cytopathologist) service, follow up of cases which are expensive ${ }^{7}$. In Bangladesh cytology service is available in tertiary level hospitals and few private clinics. Most of the women cannot get these facilities due to their lack of awareness as well as low socioeconomic condition $^{8-12}$. Though the incidence of cervical cancer are more common in low socioeconomic group and considering cost and availability of technical support, few similar scale screening programme of colposcopic examination of VIA (Visual Inspection of Cervix with acetic acid) positive cases have been started with the aim to reduce death from cervical cancer ${ }^{5}$. In this programme, VIA test is done in symptomatic women. Only VIA positive cases are selected for colposcopic examination. VIA test is considered as an accessible screening method for colposcopy in the field level because it is easy, quick and cost effective compared to pap smear as the test can be done by trained paramedics. This present study was undertaken to see the socio-demographic characteristics and incidence of CIN of uterine cervix among of VIA positive women

\section{Methodology}

This descriptive cross sectional study was carried out in the Department Of Pathology at
Bangabandhu Sheikh Mu1ib Medical University (BSMMU), Dhaka, Bangladesh during the period of July 2007 to June 2008 for one (01) year. All the cases were selected from cervical cancer screening program based on VIA (visual inspection of cervix with acetic acid) test founded by United Nation Population Fund and Government of Bangladesh (GOB) in the Department of Gynaecology and Obstetrics, BSMMU, Dhaka. VIA test is done with 3 to 5\% acetic acid. Patients who were colposcopically positive for cervical intraepithelial neoplasia and early invasive carcinoma or patients who are colposcopically negative but clinically suspicious for cervical neoplasia were included in this study. Menstruating women or P/V bleeding present during the time of examination, obvious clinically malignant growth at the cervix, patient below 18 years of age and unmarried women were excluded from this study. The clinical history was obtained by taking history with particular attention to age, age at marriage, parity, history of contraceptives, abnormal per vaginal discharge and post coital bleeding. The cervix was examined on naked eye by Cusco's speculum to see whether it was healthy or not. Then it was examined by the colposcope after applying 3 to 5\% acetic acid and colposcopic findings were collected from colposcopy unit in the Department of Gynaecology and Obstetrics at BSMMU, Dhaka. VIA positive cases were underwent colposcopy guided LEEP biopsy.

\section{Result}

A total of 63 patients of different age group were selected from patients attending at the department of Gynaecology and obstetrics, BSMMU. The age of 63 patients ranged from 20 years to 65 years with an average age of $34.6 \pm 9.59$ years. The patients were divided into five groups considering each decade as a single group.

Table 1: Age Distribution among the Study Population $(\mathbf{n}=63)$

\begin{tabular}{|l|c|c|}
\hline Age Group & Frequency & Percent \\
\hline 20 to 29 Years & 27 & 42.8 \\
\hline 30 to 39 years & 24 & 38.1 \\
\hline 40 to 49 years & 8 & 12.7 \\
\hline 50 to 59 years & 3 & 4.8 \\
\hline 60 to 69 years & 1 & 1.6 \\
\hline Total & $\mathbf{6 3}$ & $\mathbf{1 0 0 . 0}$ \\
\hline $\begin{array}{l}\text { Mean } \pm \text { SD } \\
\text { (Range) }\end{array}$ & $34.6 \pm 9.59$ (20 to 65 years) \\
\hline
\end{tabular}

Out of 63 cases maximum number $27(42.85 \%)$ 
cases belonged to the age group 30 to 39 years and $24(38.1 \%)$ cases were in age group 20 to 29 years, $8(12.69 \%)$ cases were in 40 to 49 years, $3(4.76 \%)$ cases were 50 to 59 years and $1(1.6 \%)$ case was in 60 to 69 years age group (Table 1 ).

Peak incidence of CIN lesions: In this study, $41(65 \%)$ cases were diagnosed as cervical intraepithelial neoplasia (CIN). Incidence of CIN-I was 10 cases, 8 cases, 2 cases and 1 case in age group 20 to 29 years, 30 to 39 years, 40 to 49 years and 50 to 59 years respectively. Number of CIN-II lesions were 5 cases, 8 cases, 4 cases in 20 to 29 years, 30 to 39 years, 40 to 49 years respectively. Among 3 cases of CIN-III, 2 cases were in 30 to 39 years age group and 1 in 50 to 59 years age groups. Most of the cases (18 cases) were in 30 to 39 years age group. The peak incidence of CIN lesions was in 30 to 39 years age group (Table 2).

Table 2: Incidence of CIN in different age groups among the Study Population $(n=63)$

\begin{tabular}{|l|c|c|c|c|}
\hline Age Group & CIN & CIN & CIN & Total \\
II & III & \\
\hline 20 to 29 Years & 10 & 5 & 0 & 15 \\
\hline 30 to 39 Years & 8 & 8 & 2 & 18 \\
\hline 40 to 49 Years & 2 & 4 & 0 & 6 \\
\hline 50 to 59 Years & 1 & 0 & 1 & 2 \\
\hline 60 to 69 Years & 0 & 0 & 0 & 0 \\
\hline Total & $\mathbf{2 1}$ & $\mathbf{1 7}$ & $\mathbf{3}$ & $\mathbf{4 1}$ \\
\hline
\end{tabular}

Age at marriage: Among 63 cases, 23(36.5\%) cases had history of marriage before 18 years of age and 40(63.4\%) cases after 18 years of age. Among 23 cases of early marriage, $8(34.7 \%)$ cases were in CIN-I; 7(30.4\%) cases were in CIN-II; 3(13\%) cases were in CIN-III and $1(4.3 \%)$ case in CIS. Remaining 40 cases had history of marriage after 18 years, CIN-I was diagnosed in $13(32.5 \%)$ cases and $10(25 \%)$ cases were in CIN-II (Table 3$)$.

Table 3: Comparison of Cervical Lesions In Relation to Age at Marriage

\begin{tabular}{|l|c|c|c|}
\hline \multirow{2}{*}{ CIN } & \multicolumn{2}{|c|}{ Age at Marriage } & Total \\
\cline { 2 - 4 } & $\begin{array}{l}\text { Before } \\
18 \text { years }\end{array}$ & $\begin{array}{l}\text { After } 18 \\
\text { years }\end{array}$ & \\
\hline CIN-I & 8 & 13 & 21 \\
\hline CIN-II & 7 & 10 & 17 \\
\hline CIN-III & 3 & 0 & 3 \\
\hline Total & $\mathbf{1 8}$ & $\mathbf{2 3}$ & $\mathbf{4 1}$ \\
\hline
\end{tabular}

Socioeconomic Groups: In the present study, stratification of socio-economic condition was done into lower, middle and upper class. Among 63 cases, 43(68.3\%) cases were in middle class; $14(22.2 \%)$ cases were in lower class according their per capita income and $6(9.5 \%)$ cases were in upper class (Table 4).

Table 4: Socioeconomic Status among the Study Population $(n=63)$

\begin{tabular}{|l|c|c|}
\hline $\begin{array}{l}\text { Socioeconomic } \\
\text { Status }\end{array}$ & Frequency & Percent \\
\hline Upper Class & 6 & 9.5 \\
\hline Middle Class & 43 & 68.3 \\
\hline Lower Class & 14 & 22.2 \\
\hline Total & $\mathbf{6 3}$ & $\mathbf{1 0 0 . 0}$ \\
\hline
\end{tabular}

Among 20 cases of high grade lesion (CIN-II/III) $9(45 \%)$ cases were in lower class, $8(40 \%)$ cases were in middle class and $3(15 \%)$ cases in upper class (Table 5).

Table 5: Incidence of High Grade CIN among the Different Socioeconomic Status $(n=20)$

\begin{tabular}{|l|c|c|}
\hline $\begin{array}{l}\text { Socioeconomic } \\
\text { Status }\end{array}$ & Frequency & Percent \\
\hline Upper Class & 3 & 15.0 \\
\hline Middle Class & 8 & 40.0 \\
\hline Lower Class & 9 & 45.0 \\
\hline Total & $\mathbf{2 0}$ & $\mathbf{1 0 0 . 0}$ \\
\hline
\end{tabular}

Hormonal contraceptives: In the present study, 28 $(44.4 \%)$ patients had history of taking oral pill and $7(11.1 \%)$ patients used injectable method. Rest $28(44.4 \%$ patients never used any hormonal contraceptive method. Among the contraceptive users, $13(37.1 \%)$ patients had CIN-I, 6(17.1\%) had CIN-II, 2(5.7\%) had CIN-III. Among the non-users, $8(28.5 \%)$ cases were in CIN-I; $4(14.2 \%)$ cases were in CIN-II; $1(3.5 \%)$ case was in CIN-III and 1(3.5\%) case was in carcinoma in situ (Figure II).

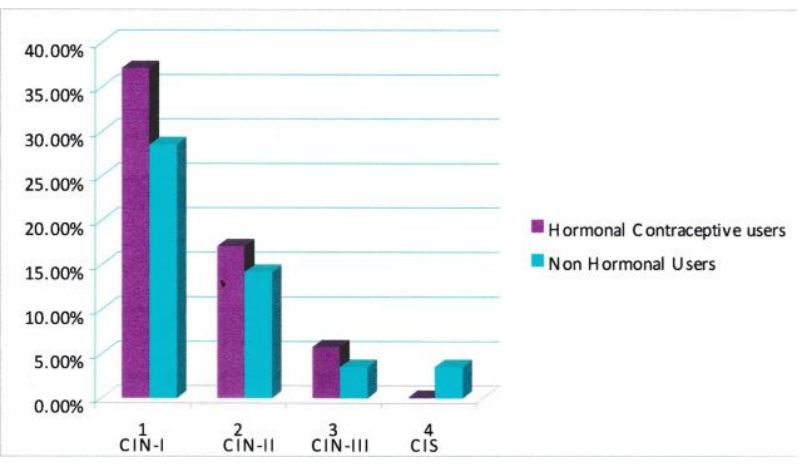

Figure I: Bar diagram showing histological pattern of cervical lesions among hormonal contraceptive and non-hormonal contraceptive users 


\section{Discussion}

A total of 63 cases were included in this study. These cases were selected after clinical examination, visual inspection with acetic acid (VIA) test and colposcopic examination. Only VIA positive cases were selected for colposcopy. Among 63 ceases. 54 cases were colposcopically positive and nine cases were colposcopically negative but clinically suspicious.

In the present study age ranged from 20 to 65 years with an average age of $34.6 \pm 9.59$ years. The highest number of patients $27(42.85 \%$ ) cases belonged to the age group 30 to 39 years followed by $24(38.1 \%)$ cases in 20 to 29 years age group. Eighteen (44\%) patients were in 30 to 39 years age group. 14(34.1\%) patients were in 20 to 29 years age group and $6(14.6 \%)$ patients were in 40 to 49 years age group. Peak incidence of cervical intraepithelial neoplasia was observed in 30 to 39 years age group in this study. Majority of CIN lesions were found in the 30 to 39 age group which was 10 to 15 years before the age of invasive cancer. Similar results have been found in several studies done by Ashrafunnesa et $\mathrm{al}^{6}$, Israt $^{7}$ and Tofazzol $^{8}$. Cervical intracpithelial neoplasia is commonly a disease of younger women. Early stage of cervical neoplasia especially intracpithelial neoplasia is being increasingly recognized in women at $2^{\text {"d }}$ and $3^{\text {rd }}$ decade. Low grade lesion are generally observed in women 5 to 10 years younger than women who have carcinoma in situ. Such lesions were found in sexually active women. In a study cervical intracpithelial neoplasia were mostly detected in women in their twenties ${ }^{3}$. Ashrafunnessa et $\mathrm{al}^{6}$ observed mild dysplasia occurs in teenagers. In another study carcinoma in situ has been found in lower age and one third of cases are being found in women aged less than 30 years ${ }^{9}$.

Marriage at early age is an important risk factor for cervical carcinoma. In our study, among 63 cases, total number of early marriage (below 18 years) was $23(36.5 \%)$. Out of which eight $(34.7 \%)$ cases are in CIN - 1, seven (30.4\%) cases are CIN - II and three $(13 \%)$ cases are CIN - III and one (4.3\%) case is CIS and four (17.3\%) cases are chronic cervicitis.

Among $40(63.5 \%)$ cases of marriage after 18 years shoes $13(32.5 \%)$ cases are CIN - 1, 10 (25\%) cases are CIN - 11 and 17 (42.5\%) cases are chronic cervicitis. In this study it is revealed that, majority of high grade cervical intraepithelial neoplasia and carcinoma in situ occurred in patients who had early age at marriage. Similar results were observed in study done by Ashrafunnessa et $\mathrm{al}^{6}$.

Low socioeconomic condition is another risk factor for cervical neoplasia. In this study. 20 cases had high grade neoplasia (CIN II/III). Of which 8 $(40 \%)$ cases were in middle class, $9(45 \%)$ were in lower class and three (15\%) cases in upper class. Similar results were found in a study done by Ashrafunnessa et $\mathrm{al}^{6}$.

In the present study, a large number of patients have given the history of taking contraceptive drugs. Among these $28(44.4 \%)$ cases have taken oral contraceptive pills and 7(11.1\%) patients have used injectable method. Rest 28(44.4\%) patients never used any hormonal contraceptive method. Among the contraceptive users, $13(37.1 \%)$ patients had CIN-I, 6(17.1\%) had CIN-II, 2(5.7\%) had CIN-III. Among the non-users, $8(28.5 \%)$ cases were in CIN-I; $4(14.2 \%)$ cases were in CIN-II; $1(3.5 \%)$ case was in CIN-III and $1(3.5 \%)$ case was in carcinoma in situ. Ashrafunnessa et $\mathrm{al}^{6}$ have reported similar result and have added that hormonal contraceptive users are more in risk of development of CIN in uterine cervix.

\section{Conclusion}

In conclusion middle age women are most commonly suffering with CIN. The peak incidence of CIN is in young adult women. Majority are reported about marriage after 18 years of age. Most of them are coming from low socioeconomic condition. Oral contraceptive pill users are a great number of patients. Further large scale study should be conducted to see the real scenario.

\section{References}

1. Parkin DM, Bray F, Ferlay J, Pisani P. Estimating the world cancer burden: Globocan 2000. International Journal of Cancer. 2001;94(2):153-6

2. Notani PN. Global variation in cancer incidence and mortality. Current science. 2001;81(5):465-74

3. Shafi MI. Premalignant and malignant disease of the cervix. Dewhurst's Book of Obstetrics and Gynaecology. 7th ed. Blackwell Publishing. 2007:614-24

4. Sultana N, Begum HA, Nahar N, Jesmin A, Ara I, Mallick HE, Tasnim A. Perception of genital cancer among women attending the OPD of tertiary care hospital in old part of Dhaka city. Journal of Dhaka National Medical College \& Hospital. 2011;17(1):4-7

5. Salih MM, Alhag FT, Khalifa MA, El Nabi AH. Cervical cytopathological changes among women with vaginal discharge attending teaching hospital. Journal of Cytology. 2017;34(2):90

6. Ashrafunnessa KS, Samsuddin L, Rahman AJE, Kamal M, Kabir S. Cervical dysplasia among women attending 
gynaecology outpatient department of a teaching hospital, BJMS 2002;8(1):39-42

7. Israt T. A study on I-IPV DNA and conventional pap test for identification of cervical intraepithelial lesion and cancer. [MD Pathology Thesis], BSMMU, Dhaka, 2006

8. Tofazzol N. Study of the association of Human papilloma virus with cervical carcinoma and precancerous lesions in a group of Bangladesh women. M. Phil (Thesis), IPGMR, Dhaka, 1992

9. Jahan Y. Colposcopic findings of visual inspection of cervix with acetic acid (VIA test) positive gynaecological cases of BSMMU, BCPS dissertation, Dhaka, 2004
10. Rohan ET, Robert DB, Eduaro LF. Toward a reduction of the global burden of cervical cancer. American Journal of Obstetrics and Gaynaecology. 2003;189:37-39

11. Rosai J. Rosai and Ackerman's surgical pathology e-book. Elsevier Health Sciences; 2011 Jun 20, $9^{\text {th }}$ edition, pp. 15231551

12. Soutter W, Butler J, Tipples M. The role of colposcopy in the follow up of women treated for cervical intraepithelial neoplasia. British Journal of Obstetrics and Gynaecology 2006;113-: 511-514 